\title{
“Um mal necessário?": As amas de leite e o discurso médico-higienista nas últimas décadas do século XIX
}

\section{"A necessary evil?": The wet nurses and the medical-hygienist speech in last decades of the $19^{\text {th }}$ century}

\section{Alan Costa Cerqueira* Maihara Raianne Marques Vitória**}

\begin{abstract}
Resumo: O presente artigo propõe analisar os diferentes discursos em torno do ofício exercido pelas amas de leite contratadas pela Santa Casa de Misericórdia de Salvador nas últimas décadas do século XIX. A partir da documentação da Santa Casa e de periódicos, sobretudo a Gazeta Médica da Bahia e O Monitor, buscamos compreender o cotidiano e as estratégias de sobrevivência dessas trabalhadoras, em sua maioria pobres e "de cor", no contexto do declínio do sistema escravista e da inserção do saber médico-higienista no cuidado à criança. O período foi marcado pelas constantes tentativas de regulamentação do trabalho dessas mulheres e da associação da prática da amamentação mercenária a um costume atrasado e retrógrado, que não condizia com os ideais de modernização propostos pelos médicos e autoridades.
\end{abstract}

Palavras-chave: Amas de leite; puericultura; trabalho urbano.

Abstract: This article analyses different discourses about the work of wet nurses hired by the Santa Casa de Misericordia de Salvador during the last decades of the 19th century. Based on Santa Casa's sources and the newspapers, especially Gazeta Medica da Bahia and $O$ Monitor, we intend to understand the daily life and survival strategies of these working women, mostly of them poor and 'coloured', in a context shaped by the decline of the proslavery system and emergence of medical-hygienic knowledge with child care. This context

* Mestre em História pela Universidade Federal da Bahia (UFBA). Doutorando em História Social pela mesma instituição. ORCID: https://orcid.org/0000-0003-3088-7012. E-mail: alancrq@gmail.com.

** Mestre em História pela Universidade Federal da Bahia (UFBA). Doutoranda em História Social pela mesma instituição. ORCID: https://orcid.org/0000-0002-1584-4762. E-mail: maiharamarques1@gmail.com. 
was also specifically featured by attempts of regulation of the wet nurses working and ideas about breastfeeding mercenary as a backward custom not consistent with modern practices from doctors and authorities.

Keywords: wet nurses; childcare; urban labour.

\section{Apresentação}

DURANTE O SÉCULO XIX, as amas de leite, como eram denominadas as mulheres que amamentavam os filhos alheios, foram peça fundamental como força de trabalho urbana, fossem elas escravizadas, libertas ou livres. De acordo com o local de trabalho, poderiam ser classificadas como internas - aquelas que prestam serviços em domicílios familiares ou no interior das instituições, como asilos ou orfanatos - ou externas, que recebiam os bebês em sua própria residência. A Santa Casa de Misericórdia de Salvador, instituição assistencial secular, que, dentre outras atribuições, acolhia as crianças abandonadas por meio da roda dos expostos, utilizou-se largamente dos serviços dessas mulheres para cuidar dos bebês enjeitados em seus primeiros anos de vida.

Ao observar a documentação da Santa Casa de Salvador, há um aspecto que nos chama bastante atenção: as amas de leite ou criadeiras que se empregavam junto à instituição, mediante o pagamento de uma pequena quantia mensal para se responsabilizarem pela criação dos bebês deixados na roda, eram mulheres pobres e, em sua maioria, não brancas. No contexto das teorias raciais recém-importadas da Europa, a prática da amamentação mercenária ganhou a conotação de costume atrasado e retrógrado, e sobre as amas passa a recair a culpa sobre o adoecimento e a morte das crianças, sob a justificativa de que, através do leite, eram passadas todas as enfermidades físicas e vícios morais associados aos africanos e seus descendentes.

É nessa perspectiva que buscamos compreender as trajetórias das amas e criadeiras que prestavam serviço para a Santa Casa nas últimas décadas do século XIX. Por meio de discussão bibliográfica e de análise documental, sobretudo a documentação institucional da Santa Casa em cruzamento com as teses médicas defendidas no período sobre amamentação e cuidados com as crianças. Também como de periódicos, a exemplo da Gazeta Médica da Bahia, revista médica que reúne artigos e publicações científicas e O Monitor, jornal liberal que teceu diversas críticas aos métodos de criação empregados pela Santa Casa, como também aos elevados índices de mortalidade e desaparecimento de crianças do asilo, pelo que as amas também eram frequentemente culpabilizadas. 


\section{Aleitamento materno e alimento artificial}

NAS ÚLTIMAS DÉCADAS DO SÉCULOXIX, o ofício exercido pelas amas de leite foialvo de incessantes debates promovidos pelos médicos, autoridades e até mesmo por parte da imprensa. Em 1838 o médico Agostinho José Ferreira Bretas defendeu, na Faculdade de Medicina do Rio de Janeiro, a primeira tese sobre o aleitamento materno. Com o título de "A utilidade do aleitamento maternal e os inconvenientes que resultam do desprezo deste dever", Bretas buscou denunciar a "desnaturalização" do hábito do aleitamento materno. O médico também questionou os motivos da insuficiência dos instintos maternais das mulheres pertencentes às famílias mais abastadas. Suas críticas também recaíram sobre as famílias que confiavam o aleitamento dos meninos às escravas, por considerar um perigo moral aos bebês que recebiam leite de outras mulheres. O argumento era de que as "qualidades" do leite da escrava possuíam valores negativos que seriam reproduzidos pelas crianças. ${ }^{1}$

A literatura sobre as mulheres que amamentavam os filhos de outras mulheres vem crescendo, embora isso ocorra de forma secundária a outros estudos, com temas ligados à história da família, higiene pública, mulheres escravizadas e crianças abandonadas. ${ }^{2}$ Segundo o dr. Silva Araújo, médico do Asilo dos Expostos, as amas externas, juntamente com as mães, eram as principais responsáveis pela mortalidade das crianças expostas. A crença era de que essas amas, por serem movidas apenas pelo interesse financeiro, não dedicavam os devidos cuidados às crianças. O argumento do dr. Araújo era de que a pobreza cunhava a "degradação orgânica" dessas mulheres e que, aliada ao "vício da educação da baixa classe" em alimentar os bebês com as tradicionais papinhas (de farinha e água fria) causava a morte dos recém-nascidos. ${ }^{3}$ As amas eram apontadas como causadoras das mortes dos bebês, mas foi o leite dessas mulheres que ajudou a diminuir o índice de mortalidade infantil.

Outro tema importante no universo da amamentação infantil diz respeito à alimentação artificial industrializada. No último século ocorreram avanços científicos, sobretudo a partir da instituição da nutrição como campo do saber e sua contribuição sobre a importância do aleitamento materno para o desenvolvimento da criança. Embora ainda seja renitente a

1 BRETAS, Agostinho José Ferreira. Dissertação inaugural sobre a utilização do aleitamento maternal e os inconvenientes que resultam do desprezo deste dever. Rio de Janeiro, 1838, 28 p. Tese (Doutoramento) Faculdade de Medicina do Rio de Janeiro apud SILVA, Antônio Augusto Moura da. Amamentação: fardo ou desejo? Estudo histórico-social dos saberes e práticas sobre aleitamento na sociedade brasileira. Dissertação (Mestrado) - Faculdade de Medicina, Universidade de São Paulo, Ribeirão Preto, 1990. p. 50-51.

2 Ver: PAULA, Leandro da Silva de. Higiene, educação e cuidados com a infância: o discurso médico nas teses da Faculdade de Medicina do Rio de Janeiro (1840-1882). Dissertação (Mestrado) - Faculdade de Educação, Universidade Federal de Juiz de Fora, 2011; GUTIERRES, Damiana Guimarães Valente. No colo da ama de leite: prática cultural da amamentação e do cuidado das crianças na Província do GrãoPará no século XIX. Dissertação (Mestrado) - Instituto de Ciências da Educação, Universidade Federal do Pará, Belém, 2013. ALMEIDA, João Aprigio Guerra de. Amamentação - um híbrido natureza cultura. Rio de Janeiro: Editora Fundação Oswaldo Cruz, 1999; MARTINS, Luiz Carlos Nunes. No seio do debate - amas de leite, civilização e saber médico no Rio de Janeiro. 2006. Dissertação (Mestrado) - Fundação Oswaldo Cruz, Casa de Oswaldo Cruz, Rio de Janeiro, 2006; BANDINTER, Elizabeth. Um amor conquistado: o mito do amor materno. Rio de janeiro: Nova Fronteira, 1985.

3 Gazeta Médica da Bahia, Salvador, v. 4, p. 381, 1879. 
substituição do leite humano por alimentos artificiais, na segunda metade do século XIX, diversos jornais da capital baiana passaram a trazer anúncios de farinhas industrializadas. $\mathrm{Na}$ década de 1870, a farinha láctea ficou bastante conhecida na capital baiana através da força da propaganda. Essa "novidade" era vendida, muitas vezes, com anúncio: "ama de leite". Publicado no Jornal da Bahia, na quarta-feira de 19 de abril de 1876, o produto era indicado para crianças de peito e pessoas "fracas".

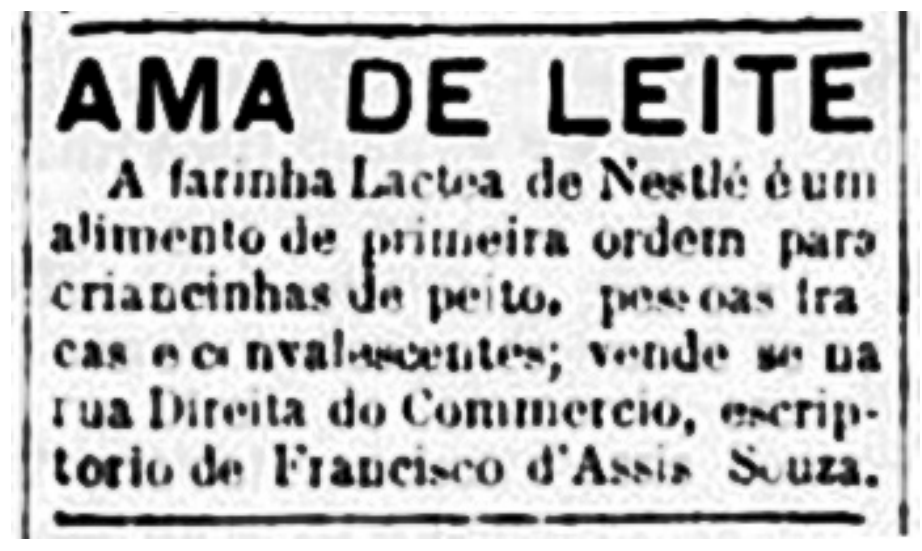

Fonte: Jornal da Bahia, Salvador, p. 3, 16 abr. 1876.

O texto que acompanhava os anúncios parecia revelar o conhecimento da prática social das misturas que algumas amas de leite davam às crianças. É muito provável que, por motivos financeiros, as amas externas que atendiam as demandas da Misericórdia não fossem o público-alvo do anúncio, entretanto, como veremos mais adiante, a instituição utilizou largamente o produto para a alimentação dos bebês criados internamente no asilo. ${ }^{4}$

Décadas antes da criação do Asilo dos Expostos, os administradores da Misericórdia acolheram crianças dentro do Recolhimento Santo Nome de Jesus, abrigo para moças que funcionava em prédio anexo ao hospital da instituição. Na tentativa de não depender das amas de leite, fizeram o uso da aleitamento artificial em que "as crianças eram alimentadas com pão molhado, mel misturado com água, ou, então, sugavam leite em trapos ou bonecas de pano". ${ }^{5}$ Sobre as razões para os usos desses alimentos, o autor acredita que as criadeiras

4 As amas contratadas pela Santa Casa recebiam um valor mensal de $8 \$ 000$ (oito mil-réis. O alimento artificial, à época, era vendido na província exclusivamente por Francisco de Assis Souza, na rua direita do Comércio, n. 8. A caixa do produto era comercializada por $40 \$ 000$ (quarenta mil réis), a caixa com cinquenta latas. Cf.: Jornal da Bahia, Salvador, p. 3, 19 abr. 1876. Disponível em: http://memoria.bn.br/DocReader/DocReader. aspx?bib=815063\& PagFis=331. Acesso em: 31 mar. 2016. Ver também: FBN. Diário de Notícias da Bahia, Salvador, p. 4, 29 set. 1877. Disponível em: http://memoria.bn.br/DocReader/DocReader.aspx?bib= 098167\&pesq=nestle\&pasta=ano\%20187. Acesso em: 31 mar. 2016. Correio da Bahia, Salvador, 16 abr. 1878, capa. Disponível em: http://memoria.bn.br/ DocReader/DocReader.aspx?bib=303488\&PagFis=1643. Acesso em: 31 mar. 2016. Outras empresas passaram a anunciar os produtos artificiais como "açúcar de leite para crianças" que, segundo o Laboratório e Farmácia Homeopática, "este produto reúne todas as vantagens desejáveis sobre o leite condensado e farinha Nestlé. O produto foi definido como "o substituto perfeito para o leite humano". O Monitor, Salvador, p. 3, 31 ago. 1880. Disponível em: http://memoria.bn.br/DocReader/ DocReader.aspx?bib=704008\&PagFis=4297. Acesso em: 29 mar. 2016. Vários exemplares dos jornais citados trouxeram informações sobre alimentação artificial entre as décadas de 1870 a 1880.

5 VENANCIO, Renato Pinto. Famílias abandonadas: assistência à criança das camadas populares no Rio de 
poderiam acumular mais de uma renda, isso se as crianças sobrevivessem. Por outro lado, os administradores tentaram empregar estas técnicas por questões financeiras: diminuir os custos com a contratação e fiscalização das amas internas e externas. Por volta de 1840 , ocorreu uma trágica tentativa de substituir as amas por alimentação artificial. A Misericórdia "tentou fazer a criação dos expostos dentro do recolhimento, confundindo o regime de um estabelecimento com outro bem diferente [...] a experiência foi bem dolorosa, porque coitado foi o desgraçado que escapou da morte". Renato Pinto Venancio calcula que os índices de mortalidade infantil na Santa Casa entre 1836 e 1837 foram de 96\%. ${ }^{6}$

Desde o final do século XVIII, já eram grandes as denúncias acerca da situação de salubridade do local. Somente em 1844, a Santa Casa decidiu separar as crianças enjeitadas dos doentes. Segundo Kátia Mattoso:

[...] a Misericórdia era primacialmente um hospital onde, num salão único e enorme, empilhavam-se desordenadamente os doentes, as amas de leite e as crianças. Foi construído um anexo para abrigar as crianças expostas mas tampouco esse espaço era mais confortável: mal ventilada, mal iluminada, úmida, a nova sala, com seus recessos para as amas de leite e seus berços apertados uns contra os outros, terminou por converter-se num verdadeiro túmulo para os recém-nascidos que abrigava enquanto se lhes encontrava na cidade uma ama de leite. ${ }^{7}$

Caso a iniciativa desse certo, é muito provável que, gradativamente, o sistema de criação fosse substituído, uma vez que seria muito mais econômico contratar amas internas, sendo que o número necessário delas era bastante inferior ao de criadeiras externas. No entanto, as fontes revelam que, na maioria dos casos, o resultado obtido foi bastante diferente do esperado. Os números de mortes aumentavam cada vez mais. Tomando por base os cálculos do médico do asilo, em 1874, a mortalidade fora de $36 \%$, no ano seguinte, aumentou para $43 \%$ e, em 1876 , atingiu a cifra de $61 \%$.

Nas páginas de O Monitor, o artigo intitulado "A respeito dos médicos dos expostos", estavam estampados os números que denunciavam a catástrofe que acontecia dentro dos muros da instituição e a relação direta com os alimentos artificiais:

O médico do asilo disse em seu relatório de 1875 que felizmente para o público ele mesmo reproduziu no diário de anteontem, estas palavras significativas: A vida dos meninos que se amamentavam tem sido menos ceifada pela morte [...] Vede, senhor, que vos iludis; pensais que morrem menos crianças e estão morrendo mais; fizestes reformas em bem da vida das pobres criaturinhas e com elas introduzistes no estabelecimento a morte. Olhai bem, senhor, que se ilude vossa aritmética e erra vossa ciência de higienista. [...] O leite condensado quer dizer $43 \%$ de crianças mortas; a farinha de Nestlé quer dizer uma mortalidade de $61 \% .^{8}$

\footnotetext{
Janeiro e Salvador - Século XVIII e XIX. Campinas: Papirus, 1999. p. 101.

6 VENANCIO, op. cit., p. 109.

7 MATTOSO, Kátia M. de Queiróz. Bahia: a cidade de Salvador e o seu mercado no século XIX. São Paulo: HUCITEC; Salvador: Secretaria Municipal de Educação e Cultura, 1978. p. 93.

8 O Monitor, Salvador, p. 1, 17 ago. 1877. Disponível em: http://memoria.bn.br/DocReader/ DocReader. aspx? $\mathrm{bib}=704008 \&$ PagFis=1397\&Pesq=\%22Nestl\%c3\%a9\%20\%22. Acesso em: 30 jun. 2020.
} 
De acordo com a redação do jornal, o médico do asilo disse ser vítima, lançando a responsabilidade pela morte dos pequeninos nos miasmas e nas amas externas, entretanto, por outras fontes, tomamos conhecimento de que boa parte dos falecimentos era, em verdade, culpa das experiências malsucedidas dos próprios doutores.

O aperfeiçoamento de técnicas no auxílio da alimentação artificial foi se tornando cada vez mais divulgado nas décadas seguintes. O anúncio abaixo passou a figurar constantemente nas edições do jornal O Monitor, durante a década de 1870:

Figura 2 - Anúncio de venda de mamadeira

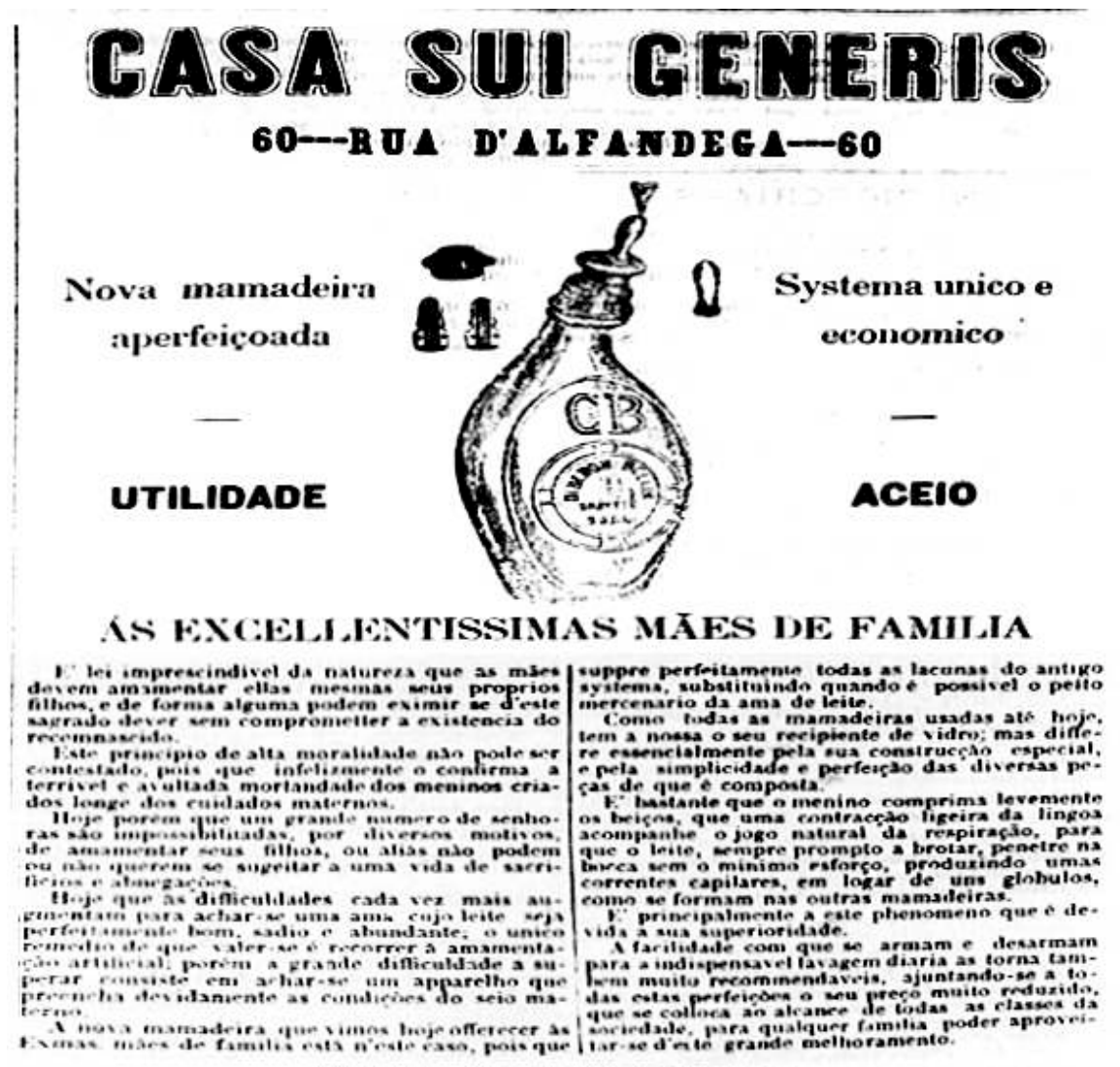

CASA SUI GENERIS

BO-NRUA D.ALFANDEGA--BO

Fonte: O Monitor, Salvador, p. 4, 6 set. 1876.

O anúncio endereçado às mães de família prometia auxiliar a criança na ingestão dos alimentos artificiais. $\mathrm{O}$ crescente comércio desses produtos teve como uma das estratégias de venda criticar as "qualidades" do leite das amas. Esse argumento, por sinal, já estava sendo difundido pelos médicos higienistas em suas publicações e defesas de teses.

As amas existiam na Europa pelo menos desde o século XVI e constantemente foram chamadas de "mercenárias", sendo criticadas por não amamentarem apenas o próprio filho, ao vender seu leite para obter renda extra. Segundo Sandra Koutsoukos, as amas livres e forras que negociavam o seu leite eram vistas como figuras que buscavam enganar os 
médicos, escondendo doenças. Havia também a ideia de que essas mulheres possuíam o leite "ralo" e "fraco" (esse mito ainda perdura nos dias atuais). Outro ponto interessante que a autora traz é que poucos se preocuparam em perceber os sacrifícios de mulheres pobres que se empregavam nesse tipo de serviço. ${ }^{9}$

\section{Salário, moradias e acordos}

SEgUNDO O MÉdICO DOS EXPOSTOS, as amas externas, movidas apenas pelo interesse pecuniário, dedicavam poucos cuidados às crianças, de modo que nem os médicos nem as irmãs do asilo poderiam prever tais comportamentos. Não faltaram a esse segmento críticas, acusações de maus-tratos às crianças e desconfianças, feitas por médicos e figuras ligadas à Misericórdia. Todavia, quem eram essas mulheres? Como eram contratadas? $\mathrm{O}$ Regulamento do Asilo definiu que as "amas internas" deveriam ser "em número proporcionado às necessidades" e amamentar os órfãos indiscriminadamente; em troca, receberiam gratificações demarcadas pelo mordomo, "em conformidade com os preços da época". ${ }^{10}$ As amas que moravam no asilo eram chamadas de amas internas, enquanto as amas de leite "externas" deveriam viver na cidade e não poderiam ser encarregadas de mais de uma criança. Algumas mulheres residiam a uma distância considerável do asilo, ainda assim, obrigatoriamente, deveriam viver dentro da cidade.

O endereço das amas era sempre registrado no momento da entrega dos bebês, mas nada garantia a permanência delas na mesma residência. Sobre essa questão, Venancio sugere que muitas das crianças poderiam morrer, sem que as criadeiras se interessassem em ir à Santa Casa informar o falecimento para receber mísera quantia a ser paga.

Algumas famílias alugavam suas escravas como amas para amamentar e cuidar de outras crianças. A Santa Casa contratava os serviços das amas livres pobres, libertas e escravizadas. Mulheres como "preta Constança", liberta, moradora da ladeira de Água de Meninos; a "cabra" Maria Antonieta, moradora da Barroquinha, casa 12; a escravizada Antônia Joaquina Silva; e a "branca" dona Maria dos Reis Paranhos, solteira, moradora da rua Nova de São Bento, prestaram serviços para a Misericórdia da Bahia. ${ }^{11}$ As formas de admissão das amas internas ocorriam mediante vistoria da irmã superiora, que deveria coletar informações sobre o nome, estado civil, domicílio, o "estado de saúde e boa qualidade do leite". ${ }^{12}$ As amas externas passavam pelos mesmos critérios para serem contratadas, porém, sua gratificação era fixada em $8 \$ 000$ réis por mês.

9 KOUTSOUKOS, Sandra Sofia Machado. Amas mercenárias: o discurso dos doutores em medicina e os retratos de amas - Brasil, segunda metade do século XIX. História, Ciências, Saúde - Manguinhos, Rio de Janeiro, v. 16, n. 2, 305-324, abr.-jun. 2009. p. 311.

10 ASCMBA - Arquivo da Santa Casa de Misericórdia da Bahia. Regulamento do Asylo dos Expostos. Salvador: Typographia do Diário, 1874. p. 7.

11 ASCMBA. Livro da roda dos expostos, est. n. 1214, est. H, fl. 1.

12 ASCMBA. Regulamento do Asylo dos Expostos, p. 6. 
Existia também a possibilidade de alguns dos enjeitados serem vendidos como escravos. ${ }^{13}$ De acordo com Maria Luiza Marcílio, não foram raros os casos em que as amas escravizavam as crianças pardas e crioulas. ${ }^{14}$ Isso era possível devido aos indícios da existência de um mercado só de crianças escravas. ${ }^{15}$

O asilo produziu um guia das amas referente a cada mês do ano. Nessa lista constava o número de matrícula da criança e os dados das amas externas e internas ("Guia das amas do mês de julho, agosto e setembro de 1862"). Também eram listadas as amas que não possuíam guia. Isso tudo funcionava como forma de controlar essas mulheres. ${ }^{16} \mathrm{Em}$ uma dessas fichas, com o número 12.993, consta o nome do "crioulo" Domiciano Dias de Mattos, que foi entregue em 22 de julho de 1861 para Maria da Conceição, como forma de legitimar a entrega. Havia vários rabiscos referentes ao pagamento de $8 \$ 000$ (oito mil-réis) mensais realizado no primeiro ano de criação, acompanhado da indicação de apresentação do órfão a cada vencimento de mês, junto com o atestado de vacina. ${ }^{17}$

Conforme o ciclo de migração europeia crescia no Brasil, as mulheres estrangeiras passaram a disputar esses espaços. Luiz Felipe de Alencastro observa que se tornou complicado debater sobre amas de leite a partir de 1850, período de forte migração portuguesa, especialmente dos Açores. A partir dos anúncios de aluguéis, o historiador observa a forma sutil de como: "inverte o prenome pessoal se, mudando a partícula apassivadora do verbo pronominal em objeto direto, ativo: uma mucama é posta à alugar-se pelo seu proprietário, a senhora livre se aluga ela própria". 18

Além dessas duas categorias, amas internas e externas, havia as "amas-secas", ou simplesmente criadeiras. Essas mulheres cuidavam das crianças "desmamadas" e passavam por critérios de seleção e fiscalização. No Asilo dos Expostos, o período de amamentação era suspenso depois de o exposto completar um ano, o prazo era estendido se constatada alguma necessidade. O órfão era "dado a criar" para as "criadeiras" pelo valor de $4 \$ 000$ (quatro mil-réis) por mês, válidos até completar seis anos de idade. Em seguida, o acordo era encerrado e a criança retornava ao asilo para o período de educação.

Em um universo de 292 matrículas e contratos de saída dos expostos, apenas 20 crianças continuaram com suas criadeiras até completar a maioridade. A documentação da Misericórdia mostra alguns casos de entrega das crianças para pessoa interessada em criá-la, sem ônus algum para instituição, "por mero amor de criação, ou por algum outro

13 VENANCIO, op. cit., p. 132

14 MARCÍLIO, Maria Luiza. Amas de leite mercenárias e crianças expostas no Brasil oitocentista. In: RIZZINI, Irene (org.). Olhares sobre a criança no Brasil - séculos XIX e XX. Rio de Janeiro: EDUSU/Amais, 1997. p. 157.

15 REIS, Isabel Cristina Ferreira dos. História de vida familiar e afetiva de escravos na Bahia do século XIX. Dissertação (Mestrado em História) - Faculdade de Filosofia e Ciências Humanas, Universidade Federal da Bahia, Salvador, 1998. p. 45.

16 ASCMBA. Lista das amas que não têm guias do mês de agosto de 1862, documento avulso, cx. 17, 1862.

17 ASCMBA. Ficha de entrega de Domiciano Dias de Mattos à Maria da Conceição, documento avulso, cx. $18,1862$.

18 ALENCASTRO, Luiz Felipe de. Vida privada e ordem privada no Império. In: ALENCASTRO, Luiz Felipe de (org.). História da vida privada no Brasil: Império. São Paulo: Companhia das Letras, 1997. p. 64. 
motivo inteiramente desinteressado". É possível falar em amor de criação ou o órfão seria um braço útil a ser explorado comercialmente por essas famílias pobres? Muitas vezes, a relação que se iniciava como um trabalho poderia se transformar em amor. Thomaz José de Mattos, "pardo claro", chegou ao asilo ainda recém-nascido onde permaneceu por alguns dias até ser entregue para Maria Geralda dos Santos no final de maio de $1864 .{ }^{19}$ A criação cessou quando o menino completou seis anos.

Thomaz retornou ao asilo para estudar e, anos mais tarde, Maria entrou com petição junto ao provedor dr. Francisco Rodrigues da Silva no dia 20 de dezembro de 1877. De acordo com o mordomo dos expostos, Maria "vinha assinar o presente termo para surtir os necessários efeitos obrigando-se a sustentar, vestir e tratar na moléstia o referido exposto sem dispêndio algum para a Santa Casa". A Misericórdia se reservava a fiscalizar a criação até que o exposto atingisse a maioridade. Maria era humilde e não sabia escrever, para isso o escrivão da Santa Casa, João Bernardino Franco Lima, assinou o documento como fiador da requerente. ${ }^{20}$ É possível que Maria tenha esperado o exposto encerrar o período de educação para retornar a sua companhia. Isso não descarta a hipótese do pedido ter sido realizado justamente para também explorar a força de trabalho de Thomaz.

Ocorreram alguns episódios em que a criança não permanecia muito tempo longe da mulher que o criou, inclusive entrava-se com petição no momento em que o exposto completava seis anos. Jacinto Thomaz de Mattos teve essa sorte. Enjeitado com um ano, em 1869, o menino pardo foi criado por Maria Magdalena do Nascimento. Em 1874 Maria agiu como sua homônima, citada anteriormente, e compareceu à sala dos despachos da Santa Casa com o documento em mãos que lhe concedia o direito de criar Jacinto sem nenhum gasto por parte da irmandade. ${ }^{21}$ Nesse caso, parecem evidentes os verdadeiros interesses por trás dessa petição. Ainda que se queira acreditar na existência de sentimentos construídos entre ama e exposto, há um problema - dentro das relações de classe e gênero - que indica outro aspecto a ser considerado. Foi descartada a hipótese que relaciona a escolha da criança por parte das amas/criadeiras através de critérios raciais, uma vez que o padrão não destoa do percentual de crianças por cor. Entretanto, das 20 crianças que viveram em companhia de seus criadores até completar maioridade, apenas uma era do sexo feminino.

Há duas considerações sobre a questão: a Santa Casa estimulava a criação externa gratuita dos meninos sem precisar ter gastos, por sua falta de preparo e estrutura para mantê-los; a incidência de petições para criação prolongada de órfãos do sexo masculino pode indicar eventuais situações de exploração da sua mão de obra.

19 ASCMBA. Livro de matrícula e serviço dos expostos, n. 1216, est. H, 1870-1894, fl. 52.

20 ASCMBA. Livro $1^{\circ}$ de termos de saída de expostos, n. 1219, est. $\mathrm{H}, 1871-1893$, fl. 29.

21 ASCMBA. Livro de matrícula e serviço dos expostos, n. 1216, est. H, 1870-1894, fl. 35. Ver também: ASCMBA. Livro $1^{\circ}$ de termos de saída de expostos, n. 1219, est. $\mathrm{H}, 1871-1893$, fl. 14. 


\title{
O avanço do movimento médico-higienista
}

O JORNAL GAZETA MÉDICA DA BAHIA foi um dos principais canais de comunicação do projeto médico-higienista em Salvador, como também o principal veículo da imprensa baiana oitocentista preocupado em atacar as amas de leite e criadeiras. Para esses médicos, o alto índice de mortalidade infantil no Asilo dos Expostos se dava ao "pouco cuidado que as amas externas prestam às crianças [...] apenas pelo interesse pecuniário é que algumas vão ali tirá-las". ${ }^{22}$ O texto ainda reconhece que a maior parte dessas mulheres eram paupérrimas, "nas quais têm impresso seu cunho de degradação orgânica e miséria e as privações continuadas". O argumento era de que mesmo havendo amas fortes e sadias, as crianças apareciam com problemas de estômago e intestino devido às tradicionais "papas", quase sempre de "péssima" farinha de mandioca misturada com água fria. Apesar da noção corrente de que o leite passava as "qualidades" físicas e morais para os bebês, segundo os médicos do asilo outro grande problema era o chamado "vício de educação da baixa classe". ${ }^{23} \mathrm{~A}$ farinha de mandioca era (e ainda é) um gênero de fundamental importância na mesa da população baiana. Pelo seu alto índice calórico, baixo preço e longo período de conservação, a farinha tornou-se indispensável no cardápio dos escravizados e da população pobre livre. ${ }^{24}$

Um caminho válido nos é proposto por Sidney Chalhoub, no intuito de compreender o pensamento médico no final do oitocentos, ao explicar de que forma os conceitos de "classes pobres" e "classes perigosas" tornam-se sinônimos sob o olhar dos higienistas e das autoridades brasileiras na segunda metade do século XIX. Ou seja, o cerne da questão é compreender a sutileza do discurso médico ao classificar a ociosidade como uma característica inerente ao cidadão pobre e dessa forma chegar à conclusão de que essa população vive em tais condições porque rejeita o trabalho. Desse modo, Chalhoub afirma que:

\begin{abstract}
As classes pobres não passaram a ser vistas como classes perigosas apenas porque poderiam oferecer problemas para a organização do trabalho e a manutenção da ordem pública. Os pobres ofereciam também perigo de contágio. Por um lado, o próprio perigo social representado pelos pobres aparecia no imaginário político brasileiro de fins do século XIX através da metáfora da doença contagiosa: as classes perigosas continuariam a se reproduzir enquanto as crianças pobres permanecessem expostas aos vícios de seus pais. ${ }^{25}$
\end{abstract}

De modo geral, a tentativa de controle da medicina sobre a saúde e as práticas de amamentação era uma centelha das incursões médicas diante da infância e sobre o próprio corpo feminino. É preciso ter em mente que a medicina, além de não ser uma instituição homogênea e coerente com os interesses das autoridades públicas, operou por um longo

22 Gazeta Médica da Bahia, Salvador, v. 4, série 3, p. 381, 1879.

23 Gazeta Médica da Bahia, Salvador, v. 4, série 3, p. 381-382, 1879.

24 REIS, João J.; AGUIAR, Márcia G.D. de. "Carne sem osso e farinha sem caroço": o motim de 1858 contra a carestia na Bahia. Revista de História, São Paulo, n. 135, p.133-160, 1996

25 CHALHOUB, Sidney. Cidade febril: cortiços e epidemias na Corte imperial. São Paulo: Companhia das Letras, 1996. p. 29. 
período em um ambiente conflituoso e de rejeição por parte dos populares. ${ }^{26}$ Ainda sobre este tema, Caroline Santos Silva demonstra como havia, entre os médicos, saberes sobre a "patologização do corpo feminino" e discursos que buscaram moldar um lugar social das mulheres. ${ }^{27} \mathrm{Em}$ contrapartida, as mulheres que defenderam teses na Faculdade de Medicina da Bahia se dedicaram, justamente, aos temas relacionados ao corpo feminino, indicando que havia uma conduta feminina de atenção em relação à saúde da mulher e ao desenvolvimento de técnicas para melhorá-la.

O Regulamento do Asilo dos Expostos previa a fiscalização das suas amas externas por meio de visitas inesperadas, como elemento surpresa, "em dias e horas incertas". ${ }^{28}$ Nos casos de enfermidade grave, em que o enjeitado não fosse levado ao hospital, o asilo descontava 15 dias do salário da ama. As amas e criadeiras que se declaravam doentes estavam sujeitas ao desligamento das tarefas.

A partir de 1870, ocorreu o aumento dos debates sobre os cuidados com o aleitamento. Tamera Marko aponta que a própria presença da figura da ama de leite passou a ser questionada e o problema se acentuava à medida que se debatia sobre as amas "de cor", através de supostos costumes "perigosos", "retrógrados" e "anti-higiênicos". Isso era parte da compreensão de que essas mulheres eram prejudiciais à saúde da criança e aos ideais de desenvolvimento e modernização de uma sociedade que almejava ser "civilizada" e "moderna". ${ }^{29}$

As amas de leite empreenderam uma relação sentimental com as crianças que amamentavam, fosse por amor ou ódio (nos exemplos em que as escravizadas eram forçadas a relegar seus filhos em virtude dos filhos de outras mulheres). Sandra Graham explica que a afetividade presente nesse tipo de relação foi marcada por recompensas que levavam em consideração o comportamento afetivo e serviçal. Sobre as famosas fotografias de amas e crianças, a autora se questiona: "Quem sabe, talvez, algumas amas tenham ganhado um retrato seu, tirado em estúdio de fotografia, com as crianças que amamentavam ou haviam amamentado, como gesto de atenção, carinho ou saudade?". ${ }^{30}$ No livro Casa-grande \& senzala, Gilberto Freyre ressalta que a escolha das escravas negras como amas de meninos foi uma prática vinda de Portugal e que existia entre as senhoras ricas. Em suas palavras:

A escolha da escrava negra para ama de menino sugere-nos outro aspecto interessantíssimo das relações entre senhores e escravos no Brasil: o aspecto

26 SAMPAIO, Gabriela dos Reis. Nas trincheiras da cura. As diferentes medicinas no Rio de Janeiro imperial. Campinas: Editora da Unicamp, 2001. p. 45-47.

27 SILVA, Caroline Santos. Com um fórceps na mão, há de se parir uma nação: ensino e prática da obstetrícia e ginecologia em Salvador (1876-1894). Dissertação (Mestrado em História) - Faculdade de Filosofia e Ciências Humanas, Universidade Federal da Bahia, Salvador, 2001. p. 49.

28 Regulamento do Asylo dos Expostos, 1874, p. 9.

29 MARKO, Tamera. A wet nurse, her masters, a folkhealer, a pediatrician, and two babies: negotiation of a 'raceless'motherhood ideal and cultural legacies of slavery in 1880 - Rio de Janeiro. In: MARKO, Tamera; WARREN, Adam (ed.). Women, ethnicity and medical authority: historical case studies in reproductive health in Latin America. CILAS Working Paper 21. San Diego: Center for Iberian and Latin American Studies/University of California, 2004. p. 60-62. Disponível em: https://escholarship.org/content/qt8q4485r0/qt8q4485r0.pdf?t=krn9fa.

30 GRAHAM, Sandra Lauderdale. Proteção e obediência: criadas e patrões no Rio de Janeiro (1860-1910). São Paulo: Companhia das Letras, 1992. p. 61. 
higiênico. De Portugal transmitira-se ao Brasil o costume das mães ricas não amamentarem os filhos, confiando-os ao peito de saloias (sic) ou escravas. [...] Com relação ao Brasil, seria absurdo atribuir-se à moda a aparente falta de ternura materna da parte das grandes senhoras. O que houve, entre nós, foi impossibilidade física das mães de atenderem a esse primeiro dever de maternidade. [...] Se casavam todas antes do tempo; algumas fisicamente incapazes de ser mães em toda plenitude. Casadas, sucediam-se nelas os partos. Um filho atrás do outro. ${ }^{31}$

Segundo Freyre, ao contrário de Portugal, onde essa prática era uma questão de moda e distinção social, no Brasil ocorria por necessidade, já que havia uma impossibilidade física das senhoras que davam à luz muito cedo, as impedindo de amamentar seus filhos. Além da justificativa etária, a fragilidade das mulheres brancas estava, também, atrelada a questões raciais, uma vez que, segundo o autor, o extenuante clima tropical exauria as forças vitais dessas jovens senhoras, ao passo que, as mulheres negras seriam fisicamente aptas para a sobrevivência nesses ambientes. ${ }^{32}$

Alencastro discute as particularidades brasileiras em relação ao modelo europeu e a polêmica em torno das escravizadas que amamentavam os filhos de outras mulheres. $O$ autor traz anúncios e debates em jornais, mostrando os argumentos prós e contras do emprego de mucamas no serviço, o que demonstra que se tratava de um tema controverso no período, dividindo, inclusive, a opinião dos doutores. Um dos argumentos contrários ao leite da escrava era de que a criança iria desenvolver costumes e hábitos dos cativos e que havia uma forte influência europeia sobre as "qualidades" culturais da mãe que seriam passadas pelo leite. O contra-argumento de um respeitável médico do Rio de Janeiro, Antônio Ferreira Pinto, era de que a cativa trataria a criança com todo o amor, motivada por possíveis recompensas ou alforria. $^{33}$

Depois de 1850, especialmente nas décadas finais avançadas do século XIX, nota-se nas páginas dos jornais a tentativa de se afirmar a imagem do país mergulhado no afã "civilizatório", em busca da "europeização" dos costumes. Existia a crença de que o leite transmitia às crianças qualidades culturais, isso explica as críticas às amas negras. Acreditava-se também que o leite poderia transmitir doenças físicas como a febre amarela, cólera, tuberculose, sífilis, vermes, lepra, entre outras doenças. ${ }^{34}$

O movimento científico-higienista buscava se legitimar enquanto saber através das Faculdades de Medicina, de publicações em artigos, jornais e literatura, ou por meio das Juntas de Higiene. ${ }^{35}$ Além do combate às práticas populares de cura, o principal discurso estava voltado para construir um projeto civilizador, baseado no controle, diagnóstico e cura

31 FREYRE, Gilberto. Casa-grande \& senzala: formação da família brasileira sob regime patriarcal. $34^{a}$ ed. Rio de Janeiro: Record, 1998. p. 359-360.

32 Ibidem, p. 360.

33 ALENCASTRO, op. cit., p. 64-66.

34 As teses médicas da época oferecem um amplo repertório de doenças que seriam transmitidas a partir do leite. Ver: GRAHAM, op. cit., p. 130-131.

35 REIS, João José. A morte é uma festa: ritos fúnebres e revolta popular no Brasil do século XIX. São Paulo: Companhia das Letras, 1991. p. 250-251; MARTINS, op. cit., p. 85. 
dos problemas que assolavam a nação, especialmente as epidemias. O principal alvo era a população pobre. ${ }^{36}$

Os médicos higienistas e os membros da mesa administrativa da Misericórdia buscavam creditar as mazelas das crianças às mulheres das camadas mais pobres. Culpar as criadeiras parecia ser uma boa saída no momento de escrever o relatório a ser entregue ao presidente da Província. $\mathrm{Na}$ interpretação da Santa Casa, o acordo com as amas de leite findaria se surgissem indícios de "desleixo ou relaxação".

Em 1870 a Gazeta Médica da Bahia lançou uma série de incursões sobre as amas. Foram discutidas questões como amamentar as crianças nos primeiros dois meses, o aleitamento de duas em duas horas e sua repetição apenas se a criança mamar pouco a cada vez. ${ }^{37}$ No dia 28 de julho de 1871, o mordomo da instituição recebeu um ofício que mostrava que a cruzada médica havia chegado ao Asilo dos Expostos. Liderados pelo médico Antônio Mariano do Bomfim, o negociante Elysio Pereira Marinhos, o padre Gleiso e a irmã superiora se juntaram "afim de dizer o que é necessário relativamente à mudança da Casa dos Expostos, por se julgar a existente insalubre e inconveniente aos mesmos". O relatório final também apontou a necessidade de construir um muro nos fundos do asilo, para evitar o ingresso de pessoas estranhas. ${ }^{38}$

O resultado dessa ação saiu na edição da Gazeta Médica no dia 15 de agosto de 1872, com a apresentação do relatório do estado sanitário do Asilo da Misericórdia, realizado pelo dr. Antônio Mariano do Bomfim, equivalente a 1871-1872. O "mapa" mostra que a mortalidade geral foi de $14,2 \%$, e de $37,3 \%$ para as crianças menores de um ano. No relatório geral correspondente aos anos de 1857 a 1866, "apesar das condições vantajosas em que ali se acha o Asylo dos Expostos", a mortalidade ficou próxima aos 42\%. Porém, entre 1866 a 1868, a mortalidade geral foi de $41,9 \%$. Entre 1870 a 1871 , o resultado foi de $44,6 \%$. Estes foram números considerados "normais", visto que perdas "mais cruéis notam-se em estabelecimentos análogos de alguns dos países mais adiantados da Europa". ${ }^{39}$ De acordo com o médico:

Depois que comecei a exercer as funções de médico do asilo, tive o prazer de ver decrescer consideravelmente a mortalidade dos infelizes expostos: o que atribuo nem tanto a meu fraco auxílio como médico do estabelecimento, mas principalmente à valiosa coadjuvação que tenho sempre encontrado da parte de diversas mesas administrativas e também por parte das beneméritas irmãs de caridade [...]. ${ }^{40}$

Não obstante, é interessante perceber quais foram os motivos dos óbitos das crianças. excesso de chuva, o ar frio que entrava pelo chão do edifício e o "abaixamento de temperatura relativo". ${ }^{41}$ Chama atenção o repertório de doenças que causaram os óbitos àquele ano. $\mathrm{A}$

36 SCHWARCZ, Lilia Moritz. O espetáculo das raças: cientistas, instituições e questão racial no Brasil (18701930). São Paulo: Companhia das Letras, 1993. p. 241; CHALHOUB, op. cit., p. 29.

37 Gazeta Médica da Bahia. Salvador, p. 130, 15 jan.1870.

38 ASCMBA. Livro $1^{\circ}$ de correspondência do Mordomo do Asylo dos Expostos, n. 150, 1871, fl. 1.

39 Gazeta Médica da Bahia, Salvador, p. 2, 15, ago.1872.

40 Gazeta Médica da Bahia, Salvador, p. 2, 15 ago. 1872.

41 Gazeta Médica da Bahia, Salvador, p. 2, 15 ago. 1872. O médico parece ter se confundido com tantas 
fraqueza "congênita" foi a maior vilã, causando oito falecimentos, seguida de sarnas e tétano, ambos com seis mortes. Problemas na dentição, disenteria, febre "tyohidea", "escrophulas", convulsões, varíola, vermes, "angica", "anasarca", "colite" e abscesso na caixa torácica foram outros problemas que resultaram na morte dos órfãos. Segundo o jornal, as amas e criadeiras eram "poderosamente" responsáveis pelos elevados índices de mortalidade, devido aos "tratamentos que a estes infelizes prestam as amas externas".

Na edição de 1876, a Gazeta Médica publicou um texto intitulado: "Hygiene Pública", que tratava do projeto de regulamentação das amas de leite, plano formulado no Rio de Janeiro pelo médico Moncorvo de Figueiredo, profissional de renome na capital. ${ }^{42}$

Tem por fim este projeto estabelecer uma fiscalização legal e restrita sobre a indústria de lactação mercenária, já de si um mal necessário quando a materna é impossível ou inconveniente, e torná-la, senão de todo inofensiva à saúde das crianças, tirar-lhe ao menos grande parte da influência que ela exerce sobre a mortalidade na primeira infância. ${ }^{43}$

O projeto higienista, que passou a culpar as amas pela suposta negligência, ignorância e fraude, previa a criação de um escritório em cada província do país, em anexo à Junta Central de Hygiene Pública, na capital, e às Inspectorias de Saúde nas demais províncias. Nomeado como Direção das Amas de Leite, o local serviria para garantir administração moral e higiênica sobre a lactação das "mercenárias", impondo fiscalização direta a essas mulheres, fossem elas livres ou escravizadas. A cobrança ocorreria apenas para os senhores de escravas e procuradores que deveriam pagar $5 \$ 000$ (cinco mil-réis) pela inscrição. Equipamentos como sondas, microscópio e caixa reagente para análise de urina eram usados para analisar o estado de saúde e a "qualidade" do leite. Também foi formulada uma medida com a intenção de inibir o senhor de "forçar sua escrava a amamentar criança alheia e, quando ela aceda a esse mister, ficará seu filho garantido". ${ }^{4}$

\section{Considerações finais}

No INÍcIO DO SÉCULO XX, o mesmo movimento que desativou o uso da roda dos expostos pôs fim à figura das criadeiras externas. As crianças passaram a viver exclusivamente na Santa Casa depois do surgimento da Liga Baiana Contra a Mortalidade Infantil, que propunha um novo modelo de assistência, ao enxergar a mortalidade infantil como um problema médico-social e não mais como consequência dos "vícios" e da "debilidade moral" das mães e amas.

estatísticas. Depois de ter dito que a mortalidade decaiu no último ano, o dr. Bomfim, diz que "de 1870 a 1871 , a mortalidade naquele ano foi ainda um pouco menor que no ano de 1871 a 1872 que agora finda".

42 Gazeta Médica da Bahia. Salvador, v. 1, série 2, p. 496, jan. 1876.

43 Gazeta Médica da Bahia, Salvador, v. 1, série 2, p. 498-501, jan. 1876.

44 Gazeta Médica da Bahia, Salvador, v. 1, série 2, p. 498- 501, 1876. 
Figura 3 - Santa Casa de Misericórdia da Bahia. Pavilhão Martagão Gesteira (1934)

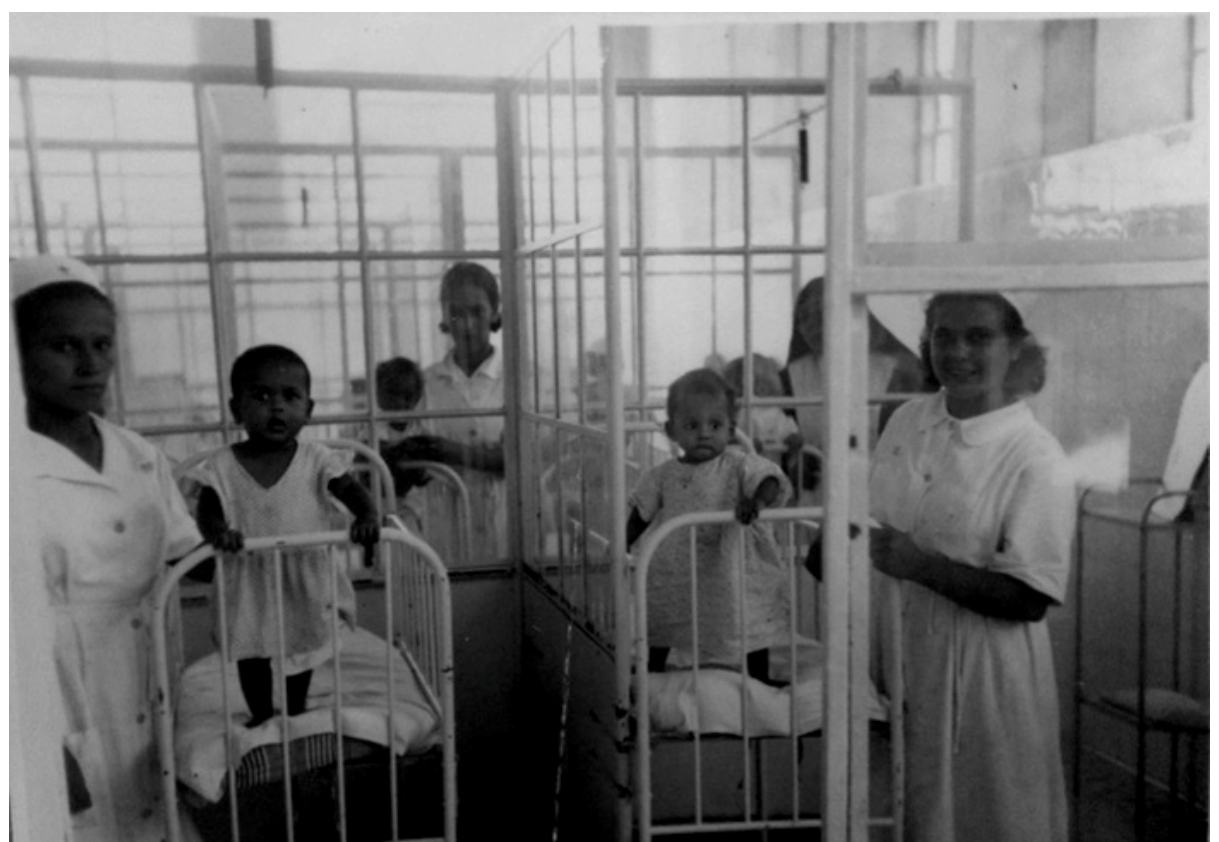

Fonte: Museu da Santa Casa de Misericórdia da Bahia - MSCMBA, documentos avulsos, 1936.

A partir de 1930, ocorreram mudanças estruturais no acolhimento das crianças da Misericórdia. A fotografia acima mostra as enfermeiras cuidando das crianças no pavilhão Martagão Gesteira. O local foi equipado com berços e pessoal para cuidar dos bebês até os três anos, quando seriam transferidos para outra ala. Foi construída, também, uma enfermaria para isolar os bebês que estivessem com alguma doença infectocontagiosa, evitando a ocorrência de surtos epidêmicos dentro da instituição. O dr. Joaquim Martagão Gesteira, professor da pediatria da Faculdade de Medicina da Bahia, que liderou o grupo formado por pediatras no movimento que ficou conhecido como a Liga Baiana Contra a Mortalidade Infantil, sugeriu uma série de mudanças à Provedoria do Asilo, dentre elas, contratação de nutrizes para amamentar naturalmente os bebês. A Liga Baiana também recomendou a construção de uma cozinha para atender às crianças com necessidades de alimentação complementar e local para a esterilização correta do leite. ${ }^{45}$

Na década de 1930, a roda foi substituída por um escritório de admissão, que possibilitava a identificação dos responsáveis pelas crianças e a declaração dos possíveis motivos do abandono. No mesmo período, a Santa Casa autorizou os médicos da liga a prestarem cuidados às crianças, sobretudo às recém-nascidas, o que impactou significativamente na diminuição da mortalidade dos expostos. Com o tempo, a importante participação das

45 COSTA, Paulo Segundo da. Ações sociais da Santa Casa de Misericórdia da Bahia. $2^{a}$ ed. Salvador: Editora Contexto e Arte Editorial Ltda, 2010. p. 52-53. Ver: RIBEIRO, Lidiane M. Filantropia e assistência à saúde da infância na Bahia: a Liga Baiana contra a mortalidade infantil, 1923-1935. 2011. Dissertação (Mestrado em História das Ciências e da Saúde) - Fundação Oswaldo Cruz, Casa de Oswaldo Cruz. Rio de Janeiro, 2011. p. 87-89. 
trabalhadoras conhecidas como "amas de leite", nos moldes do século anterior, deixou de existir. Por fim, o modelo de assistência infanto-juvenil surgido no início do século XX vigorou por quase todo o século, sendo substituído pelo movimento que resultou no surgimento do Estatuto da Criança e do Adolescente (ECA).

Recebido em 30/06/2020

Aprovado em 04/08/2020 